\title{
Assessment on artificial insemination service delivery system, challenges and opportunities of artificial insemination services in cattle production in Western zone of Tigray Region, Ethiopia
}

\author{
Teweldemedhn Mekonnen* and Leul Berhe \\ Tigray Agricultural Research Institute, Humera Agricultural Research Center, Tigray, Ethiopia.
}

Received 3 August, 2020; Accepted 23 September, 2020

\begin{abstract}
The aim of the survey was to assess artificial insemination (AI) service delivery system and identify the challenges and opportunities of Al service in cattle production in Western Zone of Tigray Region, Ethiopia. Twenty Kebeles (lowest administrative units) and 353 respondents were purposively involved in face-to-face interview. Data analysis was performed using SPSS and mainly summarized by frequency and percentages. Chi-square test was the statistical method used to test proportions of variables. There was statistically significant $(P<0.05)$ differences in Al service interruptions in both regular working hours and weekends and holiday hours. Al service interruption was a critical challenge in regular working days and in weekends and holidays. This is because $73 \%$ of the respondents reported that Al service was interrupted in Monday through Friday and $75 \%$ of the respondents also reported that Artificial Insemination Technicians (AITs) were not available to deliver Al service in weekends and holidays. Above half $(63 \%)$ of the small scale farmers reported that AITs were very poor. Most of the very poor AITs were in midland (48\%) and lowland (36\%) agro-ecologies compared to the AITs in highland (16\%) agro-ecology. Mobile Al service delivery system through motor bikes was the most common Al service delivery system used. The major challenges of Al service in order of their importance were lack of community awareness, poor animal management, unskilled AITs and inadequacy of AITs. The government and NGOs should solve the current challenges of Al service. The current approach and system of Al delivery should be restructured. Adequate numbers of skilled manpower should be assigned based on the standard numbers of breedable cows per Al center or per AIT. Moreover, agro-ecology based human management system and infrastructure development should be adequately addressed.
\end{abstract}

Key words: Communication means, Al service interruption, distance between homestead and Al service center, Al service delivery system, agro-ecology.

\section{INTRODUCTION}

The total cattle population of Ethiopia in the rural sedentary areas is estimated to be about 60.4 million.
About $55 \%$ of the total cattle population constitutes female cattle whilst $45 \%$ of the total population are

${ }^{*}$ Corresponding author. teweldem2004@gmail.com. 
male cattle. $98 \%$ of the total cattle population are local breeds whilst crossbred and pure exotic breeds accounted for just about 1.5 and $0.2 \%$, respectively (CSA, 2017/18). The most important factor for the success and profitable dairy and beef farming is efficient reproduction (Sheldon et al., 2006). Ethiopia began crossbreeding work in the early 1950s, however, the crossbreeding activities were not based on clearly defined breeding policy with regard to the level of exotic blood inheritance and the breed types to be used (Aynalem et al., 2011). The total number of crossbred female cattle produced through the crossbreeding programme for decades in the country is extremely low. This was due to the unsuccessful crossbreeding through artificial insemination (Sinishaw, 2004; Desalegn, 2008; CSA, 2011). In Ethiopia, crossbred dairy cattle are mainly crosses of Zebu and Holstein-Friesian (Nuraddis and Ahmed, 2017).

Profitability in livestock production is highly related to the reproductive success of livestock (Newton, 2014). The application of biotechnologies must include good practices in animal husbandry, animal health and nutrition, and reproduction (Bertolini and Bertolini, 2009). Artificial insemination (Al) is a valuable biotechnological tool, and most commonly used in Ethiopia over the last 30 years (Webb, 2003). Al has many advantages compared with natural service (Lima et al., 2010; Lamb and Mercadante, 2016). Al is a time dependent activity, and thus heat period could be passed away before the cows receive Al service during long journeys of cows for the service (Lemma, 2010). Practice of a good cow management and selection of cows which have good body condition score are the two most essential requirements for successful estrous synchronization and Al service (Getabalew and Alemneh, 2019). Al service in Ethiopia has not been successful to improve reproductive performance of dairy industry of the country (Desalegn et al., 2009).

Tesfay et al. (2019) reported on the assessment and analysis of the participatory agricultural production constraint appraisal of Western Zone of Tigray and noted that efficiency of Al service was poor. However, the causes and challenges for the poor efficiency of $\mathrm{Al}$ service in this region were not clearly known. Therefore, it was compulsory to assess Al service delivery system in cattle, and assess the associated risk factors and/or challenges and opportunities of Al service in the area.

\section{MATERIALS AND METHODS}

\section{Description of the study area}

The survey was carried out in Kafta Humera, Tsegede and Welkait districts. Kafta Humera district is the lowland part of Western Zone of Tigray Region, Ethiopia whereas Welkait and Tsegede districts are the highland areas of Western Zone of Tigray. Kafta Humera district has two agro-ecologies which consist of $86 \%$ lowland (kola) and $14 \%$ midland (weina dega). Welkait district also has two agro- ecologies which include $60 \%$ lowland (kola) and $40 \%$ midland (weina dega). Tsegede district has three agro-ecologies which comprise $70 \%$ lowland (kola), 22\% midland (weina dega) and 9\% high land (dega). Kafta Humera district is characterized by an altitude of 500 to $1849 \mathrm{~m}$ above sea level (masl), rainfall of $650-750$ $\mathrm{mm}$ and temperature of $25-48^{\circ} \mathrm{C}$. Welkait district is characterized by an altitude of 700 to 2354 masl, rainfall of 700 to $1800 \mathrm{~mm}$ and temperature of 18 to $25^{\circ} \mathrm{C}$. Tsegede district is also characterized by an altitude of 680 to 3008 masl, rainfall of 1200 to $2500 \mathrm{~mm}$ and temperature of 12 to $35^{\circ} \mathrm{C}$ (Tesfay et al., 2019). Moreover, Kafta Humera district was covered by $33 \%$ of forestry land and $5 \%$ of pasture land/grazing land, Welkait district had $18 \%$ of grazing land and $19 \%$ of forest land whilst Tsegede district accounted $35 \%$ of forest land and $22 \%$ of grazing land (Tesfay et al., 2019).

\section{Data collection and analysis}

\section{Sample size, sampling technique and data collection methods}

The survey was conducted in twenty rural and peri-urban Kebeles (lowest administrative units), 353 small scale farmers and 10 artificial insemination technicians (AITs), and purposive sampling was used to select Kebeles, households of small scale farmers and AITs. Kebeles with more than ten Al beneficiaries and who bred animals in two and above breeding seasons were involved in faceto-face interview. A structured questionnaire was used to collect the data from each household.

\section{Method of data analysis}

SPSS software (SPSS, v20, 2012) was used to analyze the data. The data were summarized using descriptive statistics (frequency, percentage and mean) and index method. The index method was used in ranking the challenges and opportunities of Al service:

Index $=$ sum of $(3 \times$ number of households who ranked first $+2 x$ number of households who ranked second $+1 \times$ number of households who ranked third) given for each variable divided by sum of $(3 \times$ number of households who ranked first $+2 \times$ number of households who ranked second $+1 \mathrm{x}$ number of households who ranked third) for all variables.

Moreover, an asymptotic chi-square test $\left(X^{2}\right.$-test) was computed to test significance of proportions.

\section{RESULTS}

\section{Household characteristics}

Most of the household heads $(\mathrm{HHs})(93 \%)$ interviewed were males (Table 1). The mean household family size was $6.04 \pm 1.993$. Majority $(92 \%)$ of the interviewed $\mathrm{HHs}$ were married, and most (54\%) of the interviewed $\mathrm{HHs}$ were in the age category of 46-65 years old followed by $\mathrm{HHs}(32 \%)$ in the age category of $36-45$ years old. About $45 \%$ of the interviewed $\mathrm{HHs}$ attended lower primary school whereas $31 \%$ of the $\mathrm{HHs}$ interviewed were illiterate. Majority $(80 \%)$ of the household occupation was livestock-crop mixed farming. Extensive production system (88\%) was the production system followed by the households interviewed while very few $(7 \%)$ of the households followed intensive production system (Table 
Table 1. Household marital status, Household head $(\mathrm{HH})$ gender and age, $\mathrm{HH}$ education level, household occupation and production system $(\mathrm{N}=353)$.

\begin{tabular}{|c|c|c|c|}
\hline Marital status ( $\mathrm{N}=353$ ) & Frequency (\%) & $\mathrm{X}^{2}$ & $P$ value \\
\hline Single & $2(0.6)$ & 847.782 & 0.000 \\
\hline Married & $325(92.1)$ & & \\
\hline Divorced & $12(3.4)$ & & \\
\hline Widowed & $14(4.0)$ & & \\
\hline \multicolumn{4}{|l|}{ HH gender } \\
\hline Male & $328(92.9)$ & & \\
\hline Female & $25(7.1)$ & & \\
\hline \multicolumn{4}{|l|}{$\mathrm{HH}$ age $(\mathrm{N}=353)$} \\
\hline \multicolumn{4}{|l|}{ Age categories of $\mathrm{HH}$} \\
\hline Below 25 years & $1(0.3)$ & 354.408 & 0.000 \\
\hline $25-35$ years & $21(5.9)$ & & \\
\hline $36-45$ years & $114(32.3)$ & & \\
\hline $46-65$ years & $189(53.5)$ & & \\
\hline Over 66 years & $28(7.9)$ & & \\
\hline \multicolumn{4}{|l|}{ Educational level of HHs } \\
\hline No education & $108(30.6)$ & 219.762 & 0.000 \\
\hline Lower primary school & $160(45.3)$ & & \\
\hline Upper primary school & $47(13.3)$ & & \\
\hline Secondary school & $30(8.5)$ & & \\
\hline College & $8(2.3)$ & & \\
\hline \multicolumn{4}{|l|}{ Household occupation } \\
\hline Off farm and livestock production & $28(7.9)$ & 568.144 & 0.000 \\
\hline Livestock-crop mixed farming & $281(79.6)$ & & \\
\hline Livestock production only & $5(1.4)$ & & \\
\hline Off farm and mixed farming & $39(11.0)$ & & \\
\hline \multicolumn{4}{|l|}{ Production system followed } \\
\hline Extensive production system & $312(88.4)$ & 481.773 & 0.000 \\
\hline Semi-intensive production system & $16(4.5)$ & & \\
\hline Intensive production system & $25(7.1)$ & & \\
\hline \multicolumn{4}{|l|}{ Cross tabulation test } \\
\hline Educational level * production system followed & & 19.059 & 0.015 \\
\hline
\end{tabular}

Numbers in parentheses are the percent of respondents.

1). The relationship between educational levels of household heads and the production systems followed were negatively significantly $(P \leq 0.05)$ different.

Availability of artificial insemination technicians (AITs) on regular working hours and in holidays and weekends, distance of homestead from Al service center, and means of communication used by the small scale farmers

Most $(73 \%)$ of the respondents reported that there was interruption of Al service in regular working days of Monday through Friday. Moreover, about three fourth of the respondents also indicated that AITs were not available in weekends and holidays (Table 2). However, $90 \%$ of the AITs reported a contradictory opinion that as they provided Al service in weekends and holidays. When the AITs were not available, $28 \%$ of the respondents decided to pass the date without insemination and wait the next 21 day of estrus cycle whilst $47 \%$ of the respondents used natural service. All AITs reported that the main reasons for $\mathrm{Al}$ service interruption were lack of incentives and infrastructures. 
Table 2. Availability of AITs Monday through Friday and in weekends and holidays $(N=353)$.

\begin{tabular}{|c|c|c|c|}
\hline \multicolumn{2}{|l|}{ Availability of AIT Monday up to Friday } & \multirow{2}{*}{$x^{2}$} & \multirow{2}{*}{$P$ value } \\
\hline Categories & Frequency (\%) & & \\
\hline Always available (regular service) & $97(27.5)$ & \multirow{2}{*}{71.618} & \multirow{2}{*}{0.000} \\
\hline Not always available (there was interruption) & $256(72.5)$ & & \\
\hline \multicolumn{4}{|c|}{$\begin{array}{l}\text { Cross tabulation of agro-ecology }(A E)^{*} \text { availability of AITs in Monday up to Friday } \\
\text { Always available } A E\end{array}$} \\
\hline Highland & $26(26.8)$ & & \\
\hline Midland & $66(68.0)$ & & \\
\hline Lowland & $5(5.2)$ & 39.523 & 0.000 \\
\hline \multicolumn{4}{|l|}{ Not always available* $\mathrm{AE}$} \\
\hline Highland & $47(18.4)$ & & \\
\hline Midland & 108(42.2) & & \\
\hline Lowland & $101(39.5)$ & & \\
\hline \multicolumn{4}{|l|}{ Availability of AIT in weekends and holidays } \\
\hline Yes, s/he was available & $88(24.9)$ & & 0 \\
\hline No, s/he was not available & $265(75.1)$ & 88.151 & 0.000 \\
\hline \multicolumn{4}{|c|}{ Cross tabulation of agro-ecology (AE)*availability of AITs in weekends and holidays } \\
\hline Highland & $22(25.0)$ & & \\
\hline Midland & $61(69.3)$ & & \\
\hline Lowland & $5(5.7)$ & 33.735 & 0.000 \\
\hline \multicolumn{4}{|l|}{ Not always available* $\mathrm{AE}$} \\
\hline Highland & $51(19.2)$ & & \\
\hline Midland & $113(42.6)$ & & \\
\hline Lowland & $101(38.1)$ & & \\
\hline \multicolumn{4}{|c|}{ Remedies taken by the farmers when AITs were not available } \\
\hline Pass the date without insemination & $99(28.0)$ & & \\
\hline Use natural mating & $166(47.0)$ & 30.295 & 0.000 \\
\hline AIT is available & $88(24.9)$ & & \\
\hline \multicolumn{4}{|c|}{ Availability on weekends and holidays (AITs response) } \\
\hline Available & $9(90)$ & & \\
\hline Not available & $1(10)$ & & \\
\hline
\end{tabular}

Few respondents $(6 \%)$ received $\mathrm{Al}$ service in a distance of $21-30 \mathrm{~km}$ whilst $32 \%$ of the small scale farmers obtained Al service travelling a distance of $11-20 \mathrm{~km}$. However, $50 \%$ of the AITs reported that they travelled a distance of $11-20 \mathrm{~km}$ whereas $40 \%$ of them travelled a distance of 21 to $30 \mathrm{~km}$ (Table 3). The mean number of Kebeles per AIT was $4.2 \pm 1.3$ and $60 \%$ of the AITs reported that the number of Kebeles were beyond their capacity. It was also noted that the mean number of cows and heifers inseminated per AIT/day in the breeding season was $6.7 \pm 8.8$.

\section{Payment per insemination on Al service and farmers' evaluation on the knowledge and skill of the AITs}

Few respondents (27\%) did not pay for the Al service
(Table 4). Majority (63\%) of the small scale farmers reported that the AITs were very poor whilst very few $(6 \%)$ of the respondents rated the knowledge and skill of the AITs as very good (Figure 1).

\section{Major challenges and opportunities in Al service}

There were many challenges in Al service. Based on the index ranking, lack of community awareness was the prime challenge in Al service (Table 5). Poor animal management and unskilled AITs were the second and third challenges of $\mathrm{Al}$ service, respectively. Most (78\%) of the respondents indicated that there were opportunities in Al service whilst $22 \%$ of the respondents reported that there were no opportunities. Milk market access and feed access were the first and second attractive opportunities 
Table 3. Distance of homestead from Al service center and means of communication used by the small scale farmers ( $\mathrm{N}=353$ ).

\begin{tabular}{|c|c|c|c|}
\hline Distance categories (farmers response) & Frequency (\%) & $\mathrm{x}^{2}$ & $P$ value \\
\hline Household site (AIT come) & $5(1.4)$ & \multirow{6}{*}{224.751} & \multirow{6}{*}{0.000} \\
\hline$<1$ kilometer $(\mathrm{km})$ & $12(3.4)$ & & \\
\hline $1-5 \mathrm{~km}$ & $115(32.6)$ & & \\
\hline $6-10 \mathrm{~km}$ & $87(24.6)$ & & \\
\hline $11-20 \mathrm{~km}$ & $112(31.7)$ & & \\
\hline $21-30 \mathrm{~km}$ & $22(6.2)$ & & \\
\hline \multicolumn{2}{|l|}{$\begin{array}{l}\text { Cross tabulation of agro-ecology }(\mathrm{AE})^{*} \text { distance between homestead } \\
\text { and Al service center }\end{array}$} & & \\
\hline \multicolumn{2}{|l|}{ Household site (AIT come) } & & \\
\hline Highland & $4(80.0)$ & & \\
\hline Midland & $1(20.0)$ & & \\
\hline Lowland & 0 & & \\
\hline \multicolumn{2}{|l|}{$<1$ kilometer $(\mathrm{km})$} & & \\
\hline Highland & $3(25.0)$ & & \\
\hline Midland & $9(75.0)$ & & \\
\hline Lowland & 0 & & \\
\hline \multicolumn{2}{|l|}{$1-5 \mathrm{~km}$} & & \\
\hline Highland & $41(35.7)$ & & \\
\hline Midland & $57(49.6)$ & 121.510 & 0.000 \\
\hline Lowland & $17(14.8)$ & & \\
\hline \multicolumn{2}{|l|}{$6-10 \mathrm{~km}$} & & \\
\hline Highland & $25(28.7)$ & & \\
\hline Midland & $38(43.7)$ & & \\
\hline Lowland & $24(27.6)$ & & \\
\hline \multicolumn{2}{|l|}{$11-20 \mathrm{~km}$} & & \\
\hline Highland & 0 & & \\
\hline Midland & $69(61.6)$ & & \\
\hline Lowland & $43(38.4)$ & & \\
\hline \multicolumn{2}{|l|}{$21-30 \mathrm{~km}$} & & \\
\hline Highland & 0 & & \\
\hline Midland & 0 & & \\
\hline Lowland & $22(100.0)$ & & \\
\hline Mean number of Kebeles covered by a unit of AIT & $4.2 \pm 1.3$ & Minimum of 1 & Maximum of 6 \\
\hline \multicolumn{3}{|l|}{ Did you think that you have Kebeles beyond your capacity? } & \\
\hline Yes & & $6(60)$ & \\
\hline No & & $4(40)$ & \\
\hline \multicolumn{3}{|l|}{ Distance cover (AITs response) } & \\
\hline $1-5 \mathrm{~km}$ & & $1(10)$ & \\
\hline $11-20 \mathrm{~km}$ & & $5(50)$ & \\
\hline $21-30 \mathrm{~km}$ & & $4(40)$ & \\
\hline $\begin{array}{l}\text { Number of cows and heifers inseminated per AIT per day during the } \\
\text { breeding season }\end{array}$ & \multicolumn{3}{|c|}{$6.7 \pm 8.8$ (Minimum of 1 and maximum of 30 ) } \\
\hline Means of communication (farmers response) & \multicolumn{3}{|c|}{ Percent (\%) } \\
\hline AIT visits us daily in the breeding season & \multicolumn{3}{|c|}{12.9} \\
\hline AIT comes to home when S/he wants & \multicolumn{3}{|c|}{64.9} \\
\hline We call AIT when we need him/her (mobile) & \multicolumn{3}{|c|}{64.9} \\
\hline We take our cows to the Al service center & \multicolumn{3}{|c|}{13.7} \\
\hline
\end{tabular}


Table 4. Payment per insemination on Al service and farmers 'evaluation on the knowledge and skill of the AITs ( $N=353)$.

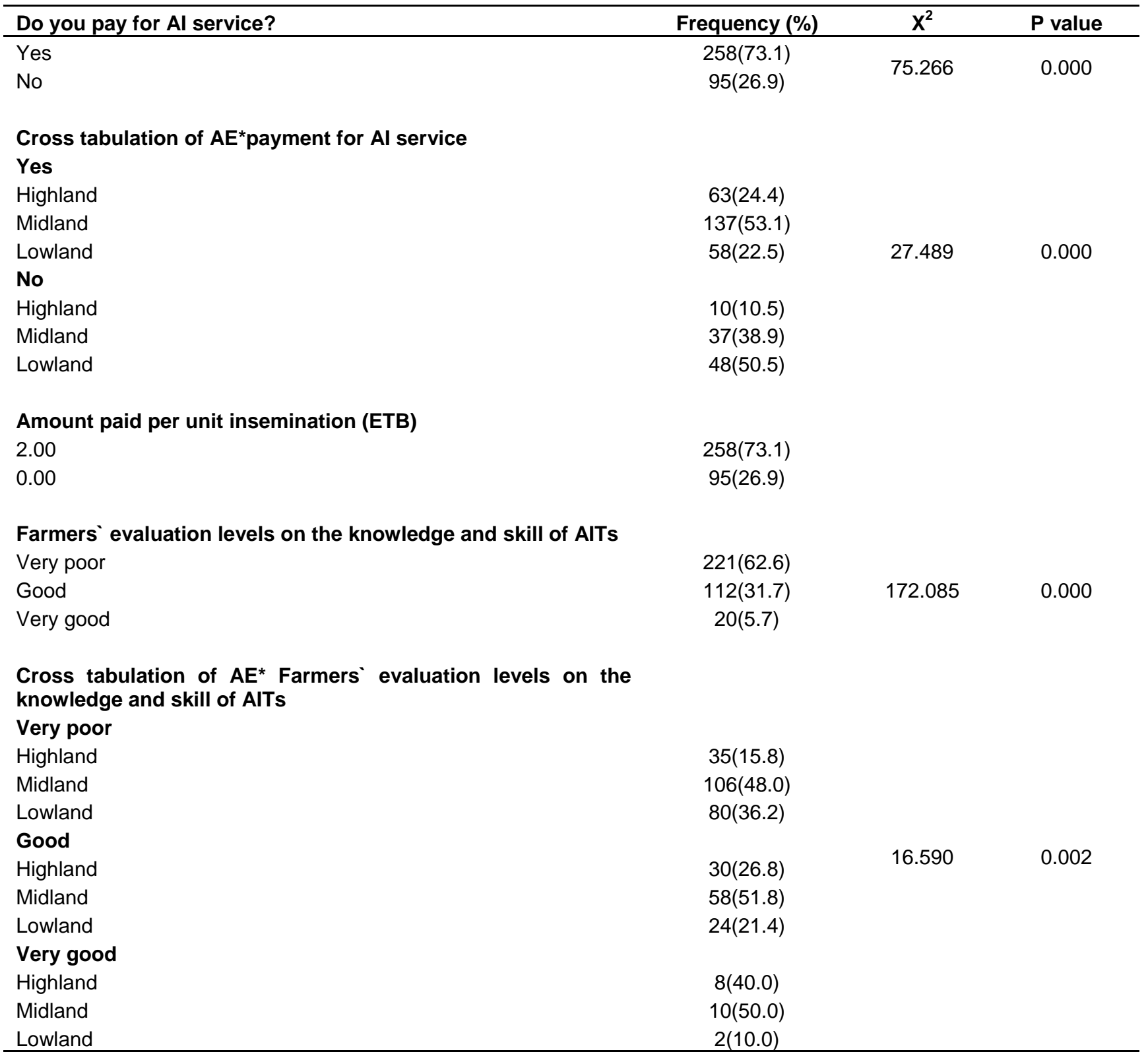

ETB=Ethiopian Birr.

in Al service, respectively (Table 5).

\section{DISCUSSION}

Majority (93\%) of the household heads ( $\mathrm{HHs}$ ) interviewed were males. The participation of female headed households in Al service was poor and future attention is needed. Most (54\%) of the interviewed $\mathrm{HHs}$ were in the age category of $46-65$ years old. $45 \%$ of the interviewed $\mathrm{HHs}$ attended lower primary school whereas $31 \%$ of the $\mathrm{HH}$ interviewed were illiterate. The small scale farmers were academically poor and calls introduction of adult education because it is basic for the success of $\mathrm{Al}$ service. However, it should be noted that change in education level in Western Zone of Tigray, Ethiopia did not influence production system; educated farmers could not shift from extensive production system to intensive production system. Only $1.4 \%$ of the respondents were involved in sole livestock farming. The awareness of the community on sole livestock farming is poor and needs to demonstrate on sustainable livestock production and nutrition and food securities. Extensive production system $(88 \%)$ was the prominent production system followed by 

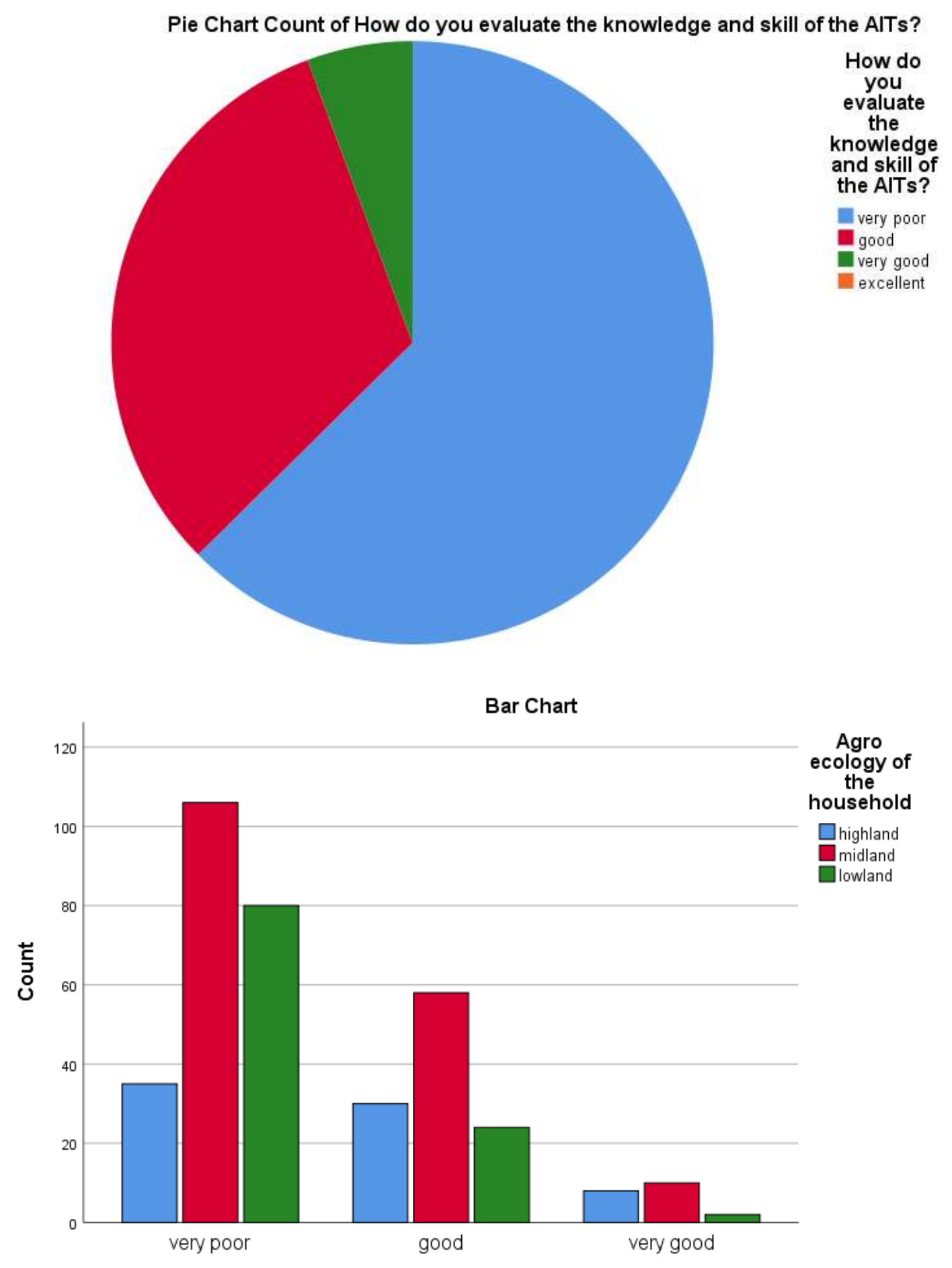

How do you evaluate the knowledge and skill of the AITs?

Figure 1. Evaluation levels of farmers on the knowledge and skill of AITs.

the households interviewed. The small scale farmers were resource poor and could not practice intensive production system.

The Al service interruption in Western Zone of Tigray, Ethiopia was a critical challenge because $73 \%$ of the respondents reported that there was service interruption in Monday through Friday and $75 \%$ of the respondents also reported that Al service was interrupted in weekends and holidays. A large proportion of Al service interruption was in midland (42\%) and lowland (40\%) agro-ecologies 
Table 5. Challenges in Al service $(\mathrm{N}=353)$.

\begin{tabular}{lcccc}
\hline Challenges & R1 & R2 & R3 & Index \\
\hline Lack of awareness in the community & 93 & 53 & 42 & 0.206 \\
Delayed time of insemination & 9 & 18 & 9 & 0.035 \\
Inadequacy of AITs & 49 & 61 & 36 & 0.147 \\
Animal management problem & 62 & 66 & 65 & 0.185 \\
Heat detection problem & 25 & 24 & 28 & 0.073 \\
Unskilled AITs & 76 & 38 & 29 & 0.160 \\
Interruptions in holydays and weekends & 19 & 44 & 62 & 0.100 \\
Disease problem & 5 & 7 & 19 & 0.023 \\
Abortion & 1 & 1 & 2 & 0.003 \\
Dystocia & 1 & 6 & 5 & 0.010 \\
Lack of infrastructure & 12 & 14 & 11 & 0.036 \\
Long distance from Al service center & 1 & 6 & 7 & 0.011 \\
Poor communication & 2 & 5 & 9 & 0.012 \\
Opportunities in Al service & & & & \\
Feed access & 116 & 8 & 0 & 0.410 \\
Market access (milk) & 145 & 22 & 0 & 0.533 \\
Best breed for crossing & 11 & 5 & 0 & 0.046 \\
Presence of irrigation & 2 & 2 & 0 & 0.010 \\
\hline
\end{tabular}

R1=Rank one, R2=Rank two, R3=Rank three, *=Begait cattle.

of Western Zone of Tigray, Ethiopia as compared to highland (18\%) agro-ecology in Monday through Friday. Almost a similar Al service interruption was reported in midland $(43 \%)$ and lowland (38\%) agro-ecologies as compared to highland (19\%) agro-ecology in weekends and holidays. The variation in $\mathrm{Al}$ service interruption across agro-ecology could be due to the differences in weather conditions. However, $90 \%$ of the artificial insemination technicians (AITs) in Western Zone of Tigray, Ethiopia reported that they did not interrupt the Al service in weekends and holidays. The present Al service interruption in Western Zone of Tigray, Ethiopia is in line with the report $76 \%$ of respondents in Tiyo district and $60 \%$ of respondents in Sagure district did not receive regular Al service (Feyera and Tegenu, 2016); Ephrem (2019) reported lack of regular and consistent Al service $(99 \%)$ and lack of weekend Al service (93\%); Ashebir et al. (2016) reported that $60 \%$ of the respondents in Eastern and Southeastern of Tigray, Ethiopia did not receive Al service in weekends and holidays, $68 \%$ of the small scale farmers of selected districts of Arsi Zone did not receive Al service regularly, and $55 \%$ of the respondents reported that there was no service in weekends and holidays (Feyera and Tegenu, 2016), Riyad et al. (2017) reported that there was Al service interruption in weekends and holidays (51\%) in Tullo district, West Hararghe, Ethiopia, 67\% of AITs were not providing Al service in the weekends in West Gojjam Zone (Malede et al., 2013), Bemrew et al. (2015) reported that there was $66 \% \mathrm{Al}$ service interruption in dairy cattle owners of Debretabour Town, Ethiopia
Nuraddis et al. (2014) reported that $59 \%$ of the small scale farmers in Selected Districts of Jimma Zone, Ethiopia did not obtain regular Al service, and Tilahun and Yohanis (2018) reported $53 \%$ of the small scale farmers in and around Adama Town did not obtain regular Al service due to different constraints.

The Al service interruption in Western Zone of Tigray, Ethiopia is not in agreement with the report of Nuraddis et al. (2017) that $85 \%$ of the small scale farmers in Western Shoa Zone, Ethiopia obtained regular Al service. This large deviation of service could be due to differences in awareness of the small scale farmers and commitment of the AITs.

When there was Al service interruption, $47 \%$ of the respondents in Western Tigray, Ethiopia used natural service whilst $28 \%$ of the respondents reported that they decided to pass the cycle without insemination. A comparable $41 \%$ of the respondents in West Gojjam Zone used natural service whilst incomparable proportion of respondents (44\%) in West Gojjam Zone decided to pass the cycle without breeding (Malede et al., 2013). Riyad et al. (2017) reported that $33 \%$ of the small scale farmers in West Haraghe, Ethiopia used natural service during Al service interruption. When the AITs were not available to deliver Al service, $28 \%$ of the small scale farmers in Western Zone of Tigray, Ethiopia decided to pass the date without insemination. This is in agreement with the report of Bemrew et al. (2015) in dairy cattle owners of Debretabour Town, Ethiopia because $29 \%$ of the small scale farmers decided to pass the date without insemination. But the proportion of small scale farmers 
(47\%) in Western Zone of Tigray, Ethiopia who used natural service and the proportion of the dairy cattle owners (28\%) of Debretabour Town, Ethiopia who used natural service are different. Moreover, $62.5 \%$ of the small scale farmers in Selected Districts of Jimma Zone, Ethiopia decided to pass the estrus cycle without insemination (Nuraddis et al., 2014) when AITs were not available to deliver Al service. These differences in decision on whether to use natural service or pass the cycle without insemination may be due to differences in awareness of the communities and on availability of bulls for natural service However, the present $\mathrm{Al}$ service interruption in Western Zone of Tigray, Ethiopia is not in line with the works of Riyad et al. (2017) who reported that $44 \%$ of the respondents in West Hararghe did not use regular Al service whilst $56 \%$ of the dairy cattle owners obtained Al service without interruption. Ashebir et al. (2016) reported that $25 \%$ of the small scale farmers in Eastern and Southeastern of Tigray, Ethiopia did not obtain regular Al service. These differences may arise from the differences in awareness of the communities, distance between homestead and Al service center and commitment of the AITs.

The distance between homestead of small scale farmers and Al service centers of Western Zone of Tigray, Ethiopia was largest in midland and lowland agroecologies compared to the distance in highland agroecology. Some of the small scale farmers (14\%) in Western Zone of Tigray, Ethiopia took their cows and heifers to the Al service centers and is not comparable with the study of Feyera and Tegenu (2016) which reported $61 \%$ of the small scale farmers took their cows to the Al service station whilst the remaining used AIT call to their vicinity. This difference may arise from differences in community awareness on Al service. Small scale farmers in West Gojjam Zone trek their cows for more than $28 \mathrm{~km}$ to Al service center due to lack of transport facilities by the AITs (Malede et al., 2013) is not in line with animal trekking distance in Western Zone of Tigray, Ethiopia because most of the animals trekked 1$20 \mathrm{Km}$ to the Al service center(s).

A daily mean of $6.7 \pm 8.8$ of cows and heifers were inseminated in each breeding season in Western Zone of Tigray, Ethiopia. Riyad et al. (2017) reported that average daily numbers of cows inseminated by AITs ranged from 1 to 10 . One local Al center for every 5,000 breedable cows is a rule of thumb in Al service (Raymond and Saifullizam, 2010). Above half $(63 \%)$ of the small scale farmers in Western Zone of Tigray, Ethiopia reported that AITs were very poor in their knowledge and skill. It was also noted that a large proportion of the small scale farmers who reported the existence of very poor AITs were in midland (48\%) and lowland (36\%) agro-ecologies compared to highland (16\%) agro-ecology. This variation may be from the differences in academic background of the AITs and the level of provision of on-job trainings. The technical knowhow of most AITs in Western Zone of
Tigray, Ethiopia was under the classification of very poor $(63 \%)$ and is not in agreement with Desalegn (2008) report on the evaluation of the technical knowhow of AITs that they were categorized as good $(57 \%)$ and very good (27\%), poor (10\%) and excellent (10\%), and Malede et al. (2013) report on AITs in West Gojjam Zone were categorized as excellent (15\%), very good $(40 \%)$, good $(23 \%)$ and poor (22\%). This difference may arise from academic background of the AITs and on the frequency of access to on-job trainings.

The main challenges of $\mathrm{Al}$ service which negatively influenced the efficiency of Al service in Western Zone of Tigray, Ethiopia were lack of awareness in the community, animal management problem, unskilled artificial insemination technicians (AITs) and inadequacy of AITs. The present challenges are similar with Ashebir et al. (2016) reported that lack of awareness (18\%) and management problem (14\%) were some of the major constraints of Al service in Eastern and Southeastern Zone of Tigray. Bemrew et al. (2015) reported inadequacy of artificial insemination technicians (AITs) $(16 \%)$, one of the major problems identified in Debretabour Town, Ethiopia, Malede et al. (2013) reported that inadequacy $(60 \%)$ of AIT (Sekela district of West Gojjam Zone), distance to Al service center and unskilled AITs were the main problems in Al service in West Gojjam Zone. Ephrem (2019) reported that lack of regular and consistent Al service (99\%), lack of weekend Al service (93\%), inadequacy of AITs (92\%) and lack of awareness (92\%) were the major constraints in Al service in selected Districts of Wolaita Zone, Ethiopia. Riyad et al. (2017) reported that shortage of AITs (18\%) and discontinuation of service on weekends and holidays $(51 \%)$ was one of the problems in Al service. Tehetna et al. (2015) reported that lack of awareness (22\%) and lack of AITs (18\%) were among the major constraints of $\mathrm{Al}$ service in and around Alamata District, Tigray, Ethiopia, Belete et al. (2018) reported animal management problems (19\%) and lack of skill in AITs $(6 \%)$, and all are similar with the current challenges in Western Zone of Tigray, Ethiopia. These all reports indicate the limited number and skill of AIT are national challenges, therefore, the government should primarily solve the limited number and skill of the AITs.

All the major constraints in Al service in smallholder dairy cows of Harar were fed shortage (93\%), heat detection problem (82\%) and Al service charge (72\%) (Engidawork, 2018) are not similar with the constraints in Western Zone of Tigray, Ethiopia. This is because all agro-ecologies and production systems could not have similar challenges; the challenges depend on the existing conditions.

\section{CONCLUSION AND RECOMMENDATION}

Education level of the households interviewed was very poor because $31 \%$ of the households were illiterate whilst 
$45 \%$ of the households attended lower primary school. There was poor Al service delivery system and poor Al coverage in Western Zone of Tigray, Ethiopia because there was little emphasis on Al service. Lack of community awareness, poor animal management, unskilled Artificial Insemination Technicians (AITs), Al service interruption and inadequacy of AITs were the main challenges in $\mathrm{Al}$ service. Therefore, many stakeholders should be involved in Al service to solve the existing challenges of Al service. The participation of female headed households in Al service was extremely poor. There were some opportunities in Al service, however, there was no effort to use the opportunities.

The mean and maximum number of Kebeles covered by a unit of AIT was four and six Kebeles, respectively. Al should not be practiced in scattered communities approach because Al service in scattered communities is not achievable. Therefore, Al should be practiced based on community-based approach to allocate adequate resources and particularly adequate number of skilled manpower should be assigned to each community. AITs should be provided frequent on-job trainings on how to detect heat and on effective insemination procedure, and they should be provided achievement-based incentives to enhance overall motivation and solve interruptions because the main reasons for Al service interruption were lack of incentives and infrastructures. The consequences of $\mathrm{Al}$ service interruption were that the farmers were exposed to uncontrolled natural service $(47 \%)$ and pass the cycle without insemination (28\%). Therefore, special commitment should be built in each AIT and institutionalized all day hours Al service system should be set. The community should also be provided adequate training on how to detect heat of cows and on proper husbandry practices. The types of communication channels were very limited (cellphone based), and many types of communication channels (magazine, newspaper, television, radio, and social media) should be used to create awareness in the community for the ease and sustainable use of Al service. There was negative relationship between educational level of household heads and production systems they followed. Educated households in the area did not practice intensive cattle production system. Household occupation system and livestock production system were basic constraints in $\mathrm{Al}$ delivery system because $80 \%$ of the households were involved in livestock-crop production system and $88 \%$ of the households followed extensive animal production system. Extensive cattle production system negatively affected Al delivery system. Therefore, Al delivery system is also successful when household occupation system is only involved in cattle production and when improved cattle management is practiced.

\section{CONFLICT OF INTERESTS}

The authors have not declared any conflict of interests.

\section{ACKNOWLEDGEMENTS}

The authors would like to thank to Agricultural Growth Program $\Pi$ (AGP- $\Pi$ ) and Humera Agricultural Research Center for their financial and transport supports.

\section{REFERENCES}

Ashebir G, Birhanu A, Gugsa T (2016). Status of Artificial Insemination in Tigray Regional State, "Constraints and Acceptability under Field Condition". Journal of Dairy, Veterinary and Animal Research 3(3):00078.

Aynalem H, Workneh A, Noah K, Tadelle D, Azage T (2011). Breeding strategy to improve Ethiopian Boran cattle for meat and milk production. IPMS (Improving Productivity and Market Success) of Ethiopian Farmers Project Working Paper 26. Nairobi, Kenya, ILRI.

Belete Y, Abraham J, Abebe A, Atilaw W, Alemayehu H (2018). Factors Affecting the Efficiency of Artificial Insemination in Dairy Cows in and Around Bishoftu (Debre Zeite), Oromia Regional State, Ethiopia. Journal of Reproduction and Infertility 9(2):28-35.

Bemrew A, Alazar W, Anmaw S, Saddam M (2015). Assessment of Problems Associated with Artificial Insemination Services in Dairy Cattle in Debretabour Town, Ethiopia. Journal of Reproduction and Infertility 6(2):48-55.

Bertolini M, Bertolini LR (2009). Advances in reproductive technologies in cattle: from artificial insemination to cloning. Revista de la Facultad de Medicina Veterinaria y de Zootecnia 56(3):184-194. Center of Agroveterinarian Sciences (CAV), Santa Catarina State University (UDES C), Brazil.

Central Statistical Agency (CSA) (2011). Ethiopian Agricultural sample survey 2010/11. Report on livestock and livestock characteristics. Central Statistical Authority (CSA), Addis Ababa, Ethiopia 2(502).

Central Statistical Agency (CSA) (2017/18). Ethiopian Agricultural Sample Survey. Report on Livestock and Livestock Characteristics (Private Peasant Holdings), Volume II, Statistical Bulletin 587, Addis Ababa, Ethiopia.

Desalegn GG (2008). Assessment of Problems/Constraints Associated with Artificial Insemination Service in Ethiopia. MSc Thesis, Addis Ababa University, Faculty of Veterinary Medicine, Debre Zeit, Ethiopia.

Desalegn G, Bekana M, Tegegne A, Blihu B (2009). Status of artificial insemination service in Ethiopia. A paper presented at the $17^{\text {th }}$ Annual Conference of the Ethiopian Society of Animal Production (ESAP), held at the Head Quarters of the Ethiopian Institute of Agricultural Research (EIAR), Addis Ababa, Ethiopia pp. 87-104.

Engidawork B (2018). Artificial Insemination Service Efficiency and Constraints of Artificial Insemination Service in Selected Districts of Harari National Regional State, Ethiopia. Open Journal of Animal Sciences 8:239-251.

Ephrem TM (2019). Constraints of Artificial Insemination Service in Selected Districts of Wolaita Zone, Ethiopia. International Journal of Research Studies in Biosciences 7(3):36-43.

Feyera GD, Tegenu G (2016). Assessment of problems and constraints associated with artificial insemination service in two selected districts of Arsi Zone. Harmoniz. Research Medical and Health Science 3(1):14-37.

Getabalew M, Alemneh T (2019) Review: Status of Artificial Insemination; Its Constraints and Estrous Synchronization in Ethiopia. SM Journal of Reproductive Health and Infertility 4(1):1008.

Lamb GC, Mercadante VRG (2016). Synchronization and artificial insemination strategies in beef cattle. Veterinary Clinics: Food Animal Practice 32:335-334.

Lemma A (2010) Factors Affecting the Effective Delivery of Artificial Insemination and Veterinary Services in Ethiopia: Ada'a Case. Presentation by Alemayehu Lemma (Addis Ababa University) to the Ethiopian Fodder Roundtable on Effective Delivery of Input Services to Livestock Development Addis Ababa, 22 June 2010.

Lima FS, Vries ADE, Risco CA, Santos JEP, Thatcher WW (2010). Economic comparison of natural service and timed artificial insemination breeding programs in dairy cattle. Journal of Dairy 
Science 93:4404-4413.

Malede B, Zerihun B, Tewodros F (2013). Assessment on Problems Associated with Artificial Insemination Services in West Gojjam Zone, Ethiopia. Advances in Biological Research 7(2):59-66.

Newton GR (2014). Increasing the efficiency of artificial insemination and embryo transfer in Capra hircus. Association of 1980 Research Directors.

Nuraddis I, Reta H, Abidu M (2014). Assessment of Problems Associated with Artificial Insemination Service in Selected Districts of Jimma Zone, Ethiopia. Journal of Reproduction and Infertility 5(2):3744.

Nuraddis I, Ahmed S (2017). Review on Reproductive Performance of Crossbred Dairy Cattle in Ethiopia. Journal of Reproduction and Infertility 8(3):88-94.

Nuraddis I, Sisay W, Tamene D, Worku G, Kidanu D, Getahun B (2017). Evaluation of Artificial Insemination Efficiency in and Around Ejere District, Western Shoa Zone, Ethiopia. Journal of Reproduction and Infertility 8(3):66-71.

Raymond AK, Saifullizam AK (2010). The Cattle Artificial Insemination Industry in Malaysia. Malaysian Journal of Veterinary Research 1(1):1-7.

Riyad J, Anwar H, Jelalu K, Kiros W (2017). Assessment on problems associated with artificial insemination service in dairy cattle in Tullo district, West Hararghe, Ethiopia. Ethiopian Veterinary Journal 21(2):62-74.

Sheldon IM, Lewis GS, LeBlanc S, Gilbert RO (2006). Defining postpartum uterine disease in cattle. Theriogenology 65:1516-1530.

Sinishaw W (2004). Study on semen quality and field efficiency of Al bulls kept at the National Artificial Insemination Center. MSc Thesis, Addis Ababa University, Faculty of Veterinary Medicine, Debre Zeit, Ethiopia.

Tehetna A, Mohammed S, Sisay W (2015). Major Constraints of Artificial Insemination in and Around Alamata District, Tigray, Ethiopia. African Journal of Basic and Applied Sciences 7(5):287290.
Tesfay B, Tsegay G, Haftu K, Teferi A, Bereket H (eds.) (2019). Participatory Agricultural Production Constraints Appraisal: Implication for Research and Development Interventions in Southern, North Western and Western Zones of Tigray. Tigray Agricultural Research Institute and Agricultural Growth Program-II, Proceedings of the Workshop held 09-15 November 2018, Capital Hotel, Wukro, Tigray, Ethiopia and Working paper no. 1.

Tilahun B, Yohanis K (2018). Assessment of Efficiency and Major Constraint of Artificial Insemination Service in Small Holder Dairy Farmers in and around Adama Town, Ethiopia. International Journal of Advanced Research in Biological Sciences 5(7):88-99.

Webb DW (2003). Artificial Insemination in Cattle. University of Florida, Gainesville. IFAS Extension, DS 58:2-5. 